\title{
Graphical Representation of Optimal Time for a Step-Stress Accelerated Life Test Design Using Frechet Distribution
}

\author{
Sana Shahab \\ Department of Statistics \& Operations Research, Aligarh Muslim University, Aligarh, India \\ Email: sana.shahb@gmail.com \\ Arif-Ul-Islam \\ Department of Statistics \& Operations Research, Aligarh Muslim University, Aligarh, India \\ Email: arifislam2@yahoo.com
}

\begin{abstract}
The article provides an approach of getting optimal time through graph for Simple step stress accelerated test of inverse weibull distribution. In this we estimate parameters using log linear relationship by maximum likelihood method. Along with this, asymptotic variance and covariance matrix of the estimators are given. Comparison between expected and observed Fisher Information matrix is also shown. Furthermore, confidence interval coverage of the estimators is also presented for checking the precession of estimator. This approach is illustrated with an example using software.
\end{abstract}

Index Terms - Accelerated Life Testing, Step-Stress, Frechet (Inverse Weibull) Distribution, Maximum Likelihood, Asymptotic Variance (AV), Optimal Time, Confidence Interval

\section{INTRODUCTION}

A more generalized case is used in step stress for the fulfillment of all the applications. Frechet distribution is important for modeling the statistical behavior of materials for a variety of engineering applications. It handles sensitive circuits very easily and is also used for opto electronic device such as solar cell, photo diodes, phototransistor, light emitting devices etc.

Due to continuous improvement in the technology, the products today have become more and more reliable with more life. It might take a long time, maybe several years, for a product to fail, which makes it difficult and even impossible to obtain the failure information under usage condition for such highly reliable products. So to get the information about the lifetime, a sample of these products is subjected to more severe operating conditions than normal ones to obtain its failure mode. This type of testing is called the accelerated life testing (ALT), where the products are put under higher than usual stresses to get more failure data in short time. The basic goal of ALT is to produce high quality product at low cost and less time.

The stress can be applied in different ways. Commonly used methods are constant stress, progressive stress and step stress:

- Constant-stress ALT: In this type, stress is kept at a constant level throughout the life of test products.
Some of the important early works in constant-stress test can be found in Kelpinski and Nelson [1], Nelson and Meeker [2].

- Progressive-stress ALT: In this type, stress applied to a test product is continuously increasing with time. See, Balakrishnana and Han [3].

- Step- stress accelerated life testing (SSALT): In this stresses are increased in stepwise manner i.e. firstly the product is subjected to a specified constant stress $S_{1}$, for a specified length of time. If it does not fail, it is subjected to a higher stress level $\mathrm{S}_{2}$ until it fails. Since higher stresses are used for better result, so accelerated testing must be approached with caution to avoid introducing failure modes that will not be encountered in normal use.

For more Information about ALTs one can consult Nelson [4]. He was the first to propose the simple stepstress scheme, with the cumulative exposure model. Many studies regarding SSALT planning have been performed based on the CE Model, see Xiong [5], Watkins [6], Zhao and Elsayed [7], Balakrishnan el al. [8], Yeo and Tang [9]. Miller and Nelson [10] obtained the optimum simple step-stress accelerated life test plans for the case where the test units have exponentially distributed life times. Bai and others [11] extended the results of Miller and Nelson [10] to the case of censoring. Khamis-Higgins [12] introduced the step stress scheme for weibull distribution using K-H model. Ali and Ammar [13] proposed Optimal Design of Step-Stress Life Test with Progressively type-II Censored Exponential Data. Tang et al. [14] have used a linear cumulative exposure model to analyze data from a SSALT using 3-parameter Weibull distribution. Bhattacharyya and Soejoeti[15] developed a tampered failure-rate model. Bhattacharyya [16] also derived an approach using a Gaussian stochastic process which was later modified and extended by Doksum and Hoyland[17].

The cumulative exposure model defined by Nelson [4] for simple step-stress testing with low stress $S_{1}$ and high stress $\mathrm{S}_{2}$ : 


$$
\mathrm{F}(\mathrm{t})= \begin{cases}\mathrm{F}_{1}(\mathrm{t}) & 0 \leq \mathrm{t}<\tau \\ \mathrm{F}_{2}\left(\mathrm{t}-\tau+\tau^{\prime}\right) & \tau \leq \mathrm{t}<\infty\end{cases}
$$

where:

$\mathrm{F}_{\mathrm{i}}(\mathrm{t})$ the cumulative distribution function(c.d.f.) of the failure time at stress $S_{i}, \tau$ is the time to change stress and $\tau^{\prime}$ is the solution of $F_{1}(\tau)=F_{2}\left(\tau^{\prime}\right)$.

On solving for $\tau^{\prime}$ we get:

$$
\tau^{\prime}=\tau\left(\frac{\theta_{2}}{\theta_{1}}\right)
$$

The Reliability function of Frechet distribution is:

$$
\mathrm{R}(\mathrm{t})=1-\exp \left(-\left(\frac{\mathrm{t}}{\theta}\right)^{-\alpha}\right) \mathrm{t}, \alpha, \theta>0
$$

The remainder of this paper is organized as follows: In Section 2 we provide the simple conditions and assumptions on which whole paper is based. Next Section 3 presents the maximum likelihood estimators (MLEs) of model as well as Fisher Information matrix. Along with this variance-covariance matrix is also discussed. Section 4 gives the confidence interval details followed by calculation of optimal time with the help of graph in section 5. Section 6 explains the simulation studies for illustrating the theoretical results. Finally, conclusions are included in Section 7.

\section{Notation:}

$\begin{array}{ll}\mathrm{K}-\mathrm{H} & \text { Khamis-Higgins } \\ \mathrm{PDF} & \text { Probability density function } \\ \mathrm{MLE} & \text { Maximum Likelihood estimator } \\ \mathrm{AV} & \quad \text { Asymptotic variance } \\ \mathrm{MSE} & \text { Mean square error } \\ \mathrm{CI} & \quad \text { Confidence Interval } \\ \mathrm{N} & \text { total sample size } \\ \mathrm{n}_{\mathrm{i}} & \text { number of units failed at stress level } \mathrm{i}, \mathrm{i}=1,2 \\ \mathrm{~S}_{0} & \text { design stress } \\ \mathrm{S}_{1} & \text { low stress } \\ \mathrm{S}_{2} & \text { high stress } \\ \alpha & \text { shape parameter } \\ \theta & \text { scale parameter } \\ \beta_{0}, \beta_{1} & \text { parameters of log linear relationship } \\ \tau & \text { time to change the stress } \\ \mathrm{F}_{\mathrm{i}}(\mathrm{t}) & \text { cumulative distribution function } \\ \mathrm{t}_{1, \mathrm{j}} & \text { observed failure times at low stress; } \mathrm{j}=1, \ldots . . \mathrm{n}_{1} \\ \mathrm{t}_{2, \mathrm{j}} & \text { observed failure times at low stress; } \mathrm{j}=1, \ldots \ldots \mathrm{n}_{2} \\ \tau^{*} & \quad \text { Optimal time } \\ & \end{array}$

\section{THE MODEL AND ASSUMPTIONS}

The Cumulative Exposure model of a test product under simple stress test is given by:

$$
G(t)= \begin{cases}G_{1}(t) & 0 \leq t<\tau \\ G_{2}\left(t-\tau+\frac{\theta_{2}}{\theta_{1}} \tau\right) & \tau \leq t<\infty\end{cases}
$$

where,

$$
G_{i}(t)=\exp \left(-\left(\frac{t}{\theta_{i}}\right)^{-\alpha}\right) ; j=1,2
$$

From (1) the PDF can be obtained by

$$
g_{i}(t)=\frac{d}{d t} G_{i}(t)
$$

Hence PDF is given by:

$$
g(t)= \begin{cases}g_{1}(t) & 0 \leq t<\tau \\ g_{2}\left(t-\tau+\frac{\theta_{2}}{\theta_{1}} \tau\right) & \tau \leq t<\infty\end{cases}
$$

where,

$$
g_{i}(t)=\exp \left(-\left(\frac{t}{\theta_{i}}\right)^{-\alpha}\right)\left[\alpha\left(\frac{t}{\theta_{i}}\right)^{-\alpha-1}\right]\left(\frac{1}{\theta_{i}}\right), t, \theta_{i}>0
$$

The cumulative distribution function of the time to failure of a test unit under simple step-stress test follows the K-H model.

The K-H model for (1) is given by:

$$
\begin{aligned}
& \mathrm{F}(\mathrm{t})= \begin{cases}\exp \left(-\left(\frac{\mathrm{t}}{\theta_{1}}\right)^{-\alpha}\right) & 0 \leq \mathrm{t}<\tau \\
\exp \left(-\left(\frac{\mathrm{t}}{\theta_{2}}\right)^{-\alpha}\right) \exp \left\{-\left[\left(\frac{\tau}{\theta_{1}}\right)^{-\alpha}-\left(\frac{\tau}{\theta_{2}}\right)^{-\alpha}\right]\right\} & \tau \leq \mathrm{t}<\infty\end{cases}
\end{aligned}
$$

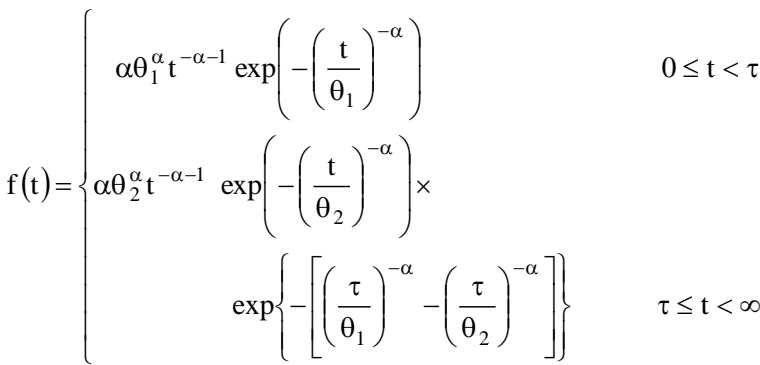

where $\log \left(\theta_{\mathrm{i}}\right)=\beta_{0}+\beta_{1} \mathrm{~S}_{\mathrm{i}}, \mathrm{i}=1,2$

Basic assumptions are:

1. Under any stress the life time of test unit follows a frechet distribution with known shape parameter $(\alpha)$.

2. Testing is done at two stresses $S_{1}$ and $S_{2}$, with $S_{1}<S_{2}$.

3. A random sample of $n$ identical products is placed on a life test. First all test units are placed on low stress $S_{1}$ and run until time $\tau$ and then it is placed at higher stress $S_{2}$ until all units fail.

4. The scale parameter $\theta_{i}$ at stress level $i, i=1,2$ is a loglinear function of stress i.e. $\log \left(\theta_{\mathrm{i}}\right)=\beta_{0}+\beta_{1} S_{\mathrm{i}}$, where, $\beta_{0}$ and $\beta_{1}<0$ are unknown parameters which is estimated by the data.

5. The lifetime of test units are independent and identically distributed.

\section{ESTIMATION PROCESS}

\section{A. Maximum Likelihood estimates}

Let $t_{i j},, i=1,2, j=1,2, \ldots . n_{i}$ be the observed failure test of a unit $\mathrm{j}$ under the stress level $\mathrm{i}$, where $\mathrm{n}_{1}$ denotes the 
number of units failed at stress $\mathrm{S}_{1}$ and $\mathrm{n}_{2}$ denotes the number of units failed at stress $S_{2}$ respectively.

The likelihood function is given by-

$$
\mathrm{L}\left(\theta_{1}, \theta_{2} ; \mathrm{t}\right)=\prod_{\mathrm{j}=1}^{\mathrm{n}_{1}}\left[\mathrm{f}_{1}\left(\mathrm{t}_{1 \mathrm{j}}\right)\right]+\prod_{\mathrm{j}=1}^{\mathrm{n}_{2}}\left[\mathrm{f}_{2}\left(\frac{\theta_{2}}{\theta_{1}} \tau+\mathrm{t}_{2 \mathrm{j}}-\tau\right)\right]
$$

The log likelihood of the likelihood function is given by:

$$
\begin{aligned}
\log l & =\sum_{\mathrm{j}=1}^{\mathrm{n}_{1}}\left[\mathrm{f}_{1}\left(\mathrm{t}_{1 \mathrm{j}}\right)\right]+\sum_{\mathrm{j}=1}^{\mathrm{n}_{2}}\left[\mathrm{f}_{2}\left(\frac{\theta_{2}}{\theta_{1}} \tau+\mathrm{t}_{2 \mathrm{j}}-\tau\right)\right] \\
\log \mathrm{l} & =\sum_{\mathrm{j}=1}^{\mathrm{n}_{1}}\left[\log \alpha+\alpha \log \left(\theta_{1}\right)-(\alpha+1) \log \left(\mathrm{t}_{1 \mathrm{j}}\right)-\left(\frac{\mathrm{t}_{1 \mathrm{j}}}{\theta_{1}}\right)^{-\alpha}\right] \\
& +\sum_{\mathrm{j}=1}^{\mathrm{n}_{2}}\left[\log \alpha+\alpha \log \theta_{2}-(\alpha+1) \log \left(\mathrm{t}_{2 \mathrm{j}}\right)\right] \\
& -\sum_{\mathrm{j}=1}^{\mathrm{n}_{2}}\left[\left(\frac{\mathrm{t}_{2 \mathrm{j}}}{\theta_{1}}\right)^{-\alpha}+\left(\frac{\tau}{\theta_{1}}\right)^{-\alpha}-\left(\frac{\tau}{\theta_{2}}\right)^{-\alpha}\right]
\end{aligned}
$$

The maximum likelihood estimates for $\beta_{0}$ and $\beta_{1}$ be obtained by solving:

$$
\begin{aligned}
\frac{\partial \log 1}{\partial \beta_{0}}= & \sum_{\mathrm{j}=1}^{\mathrm{n}_{1}}\left[\alpha+\alpha \mathrm{t}_{1 \mathrm{j}}{ }^{-\alpha} \mathrm{e}^{\alpha\left(\beta_{0}+\beta_{1} \mathrm{~S}_{1}\right)}\right]+ \\
& \sum_{j=1}^{n_{2}}\left[\begin{array}{c}
\alpha-\alpha\left(t_{2 j}^{-\alpha}-\tau^{-\alpha}\right) e^{\alpha\left(\beta_{0}+\beta_{1} S_{2}\right)} \\
-\alpha \tau^{-\alpha} e^{\alpha\left(\beta_{0}+\beta_{1} S_{1}\right)}
\end{array}\right]=0 \\
\frac{\partial \log 1}{\partial \beta_{1}}= & \sum_{\mathrm{j}=1}^{\mathrm{n}_{1}}\left[\alpha \mathrm{S}_{1}\left(1-\mathrm{t}_{1 \mathrm{j}}^{-\alpha} \mathrm{e}^{\alpha\left(\beta_{0}+\beta_{1} \mathrm{~S}_{1}\right)}\right)\right]+ \\
& \sum_{j=1}^{n_{2}}\left[\begin{array}{c}
\alpha S_{2}-\alpha S_{2}\left(t_{2 j}^{-\alpha}-\tau^{-\alpha}\right) e^{\alpha\left(\beta_{0}+\beta_{1} S_{2}\right)} \\
-\alpha S_{1} \tau^{-\alpha} e^{\alpha\left(\beta_{0}+\beta_{1} S_{1}\right)}
\end{array}\right]=0
\end{aligned}
$$

By solving the system of nonlinear equation (3) \& (4), the MLEs $\hat{\beta}_{0}$ and $\hat{\beta}_{1}$ are obtained and hence the $\hat{\theta}_{1}$ and $\hat{\theta}_{2}$ can be obtained.

\section{B. Fisher Information Matrix}

The expected Fisher information matrix is obtained by taking the negative of the expected value of the second and mixed partial derivative of $\log l$ with respect to $\beta_{0}$ and $\beta_{1}$ which is given as follows:

$$
\begin{gathered}
\mathrm{I}=\mathrm{n}\left[\begin{array}{c}
\mathrm{E}\left[-\frac{\partial^{2} \log 1}{\partial \beta_{0}^{2}}\right] \mathrm{E}\left[-\frac{\partial^{2} \log 1}{\partial \beta_{1} \partial \beta_{0}}\right] \\
\left.\mathrm{E}\left[-\frac{\partial^{2} \log 1}{\partial \beta_{0} \partial \beta_{1}}\right] \mathrm{E}\left[-\frac{\partial^{2} \log 1}{\partial \beta_{1}^{2}}\right]\right] \\
-\frac{\partial^{2} \log l}{\partial \beta_{0}^{2}}=\sum_{j=1}^{n_{1}} \alpha^{2} t_{1 j}^{-\alpha} e^{\alpha\left(\beta_{0}+\beta_{1} S_{1}\right)}+\sum_{j=1}^{n_{2}} \alpha^{2} t_{2 j}^{-\alpha} e^{\alpha\left(\beta_{0}+\beta_{1} S_{2}\right)} \\
+n_{2} \alpha^{2} \tau^{-\alpha} e^{\alpha\left(\beta_{0}+\beta_{1} S_{1}\right)} \\
-n_{2} \alpha^{2} \tau^{-\alpha} e^{\alpha\left(\beta_{0}+\beta_{1} S_{2}\right)}
\end{array}\right.
\end{gathered}
$$

$$
\begin{aligned}
-\frac{\partial^{2} \log l}{\partial \beta_{0} \partial \beta_{1}}= & -\frac{\partial^{2} \log l}{\partial \beta_{1} \partial \beta_{0}} \\
= & \sum_{j=1}^{n_{1}} \alpha^{2} S_{1} t_{1 j}^{-\alpha} e^{\alpha\left(\beta_{0}+\beta_{1} S_{1}\right)} \\
& +\sum_{j=1}^{n_{2}} S_{2} \alpha^{2} t_{2 j}^{-\alpha} * e^{\alpha\left(\beta_{0}+\beta_{1} S_{2}\right)} \\
& +n_{2} \alpha^{2} \tau^{-\alpha} e^{\alpha\left(\beta_{0}+\beta_{1} S_{1}\right)} S_{1} \\
& -n_{2} \alpha^{2} \tau^{-\alpha} S_{2} e^{\alpha\left(\beta_{0}+\beta_{1} S_{2}\right)} \\
-\frac{\partial^{2} \log l}{\partial \beta_{1}^{2}}= & \sum_{j=1}^{n_{1}} \alpha^{2} S_{1}^{2} t_{1 j}^{-\alpha} e^{\alpha\left(\beta_{0}+\beta_{1} S_{1}\right)} \\
& +\sum_{j=1}^{n_{2}} S_{2}^{2} \alpha^{2} t_{2 j}^{-\alpha} e^{\alpha\left(\beta_{0}+\beta_{1} S_{2}\right)} \\
& +n_{2} \alpha^{2} \tau^{-\alpha} e^{\alpha\left(\beta_{0}+\beta_{1} S_{1}\right)} S_{1}^{2} \\
& -n_{2} \alpha^{2} \tau^{-\alpha} S_{2}^{2} e^{\alpha\left(\beta_{0}+\beta_{1} S_{2}\right)}
\end{aligned}
$$

where,

$$
\begin{aligned}
& \mathrm{F}=\alpha^{2} \exp \left[-\left(\frac{\tau}{\theta_{1}}\right)\right]^{-\alpha}\left[\left(\frac{\tau}{\theta_{1}}\right)^{-\alpha}+1\right] \\
& \mathrm{G}=\alpha^{2}\left\{1-\left[\left(\frac{\tau}{\theta_{1}}\right)^{-\alpha}+1\right] \exp \left[-\left(\frac{\tau}{\theta_{1}}\right)\right]^{-\alpha}\right\} \\
& \exp \left[-\left(\frac{\tau}{\theta_{1}}\right)\right]^{-\alpha} \exp \left[-\left(\frac{\tau}{\theta_{2}}\right)\right]^{-\alpha} \\
& \mathrm{H}=\alpha^{2}\left(\frac{\tau}{\theta_{1}}\right)^{-\alpha} \\
& \mathrm{I}=\alpha^{2}\left(\frac{\tau}{\theta_{2}}\right)^{-\alpha}
\end{aligned}
$$

The expected Fisher information matrix is given by:

$$
I=n\left[\begin{array}{ll}
A & B \\
B & C
\end{array}\right]
$$


The Variance and Covariance Matrix for $\operatorname{MLE}\left(\hat{\beta}_{0}, \hat{\beta}_{1}\right)$ is defined as the inverse matrix of the Fisher's information matrix:

$$
\Sigma=\frac{\mathrm{n}}{\mathrm{AC}-\mathrm{B}^{2}}\left[\begin{array}{cc}
\mathrm{C} & -\mathrm{B} \\
-\mathrm{B} & \mathrm{A}
\end{array}\right]=\mathrm{I}^{-1}
$$

Elements A, B and C are given in (9).

When the exact mathematical expressions for the expectation is difficult to find then it can be approximated to the negative of the second and mixed partial derivative of $\log 1$ with respect to $\beta_{0}$ and $\beta_{1}$ evaluated at MLE. It is known as observed Fisher information matrix, given by:

$$
S=\left[\begin{array}{cc}
-\frac{\partial^{2} 1}{\partial \beta_{0}^{2}} & -\frac{\partial^{2} 1}{\partial \beta_{0} \partial \beta_{1}} \\
-\frac{\partial^{2} 1}{\partial \beta_{1} \partial \beta_{0}} & -\frac{\partial^{2} 1}{\partial \beta_{1}^{2}}
\end{array}\right]_{\beta_{0}=\hat{\beta}_{0}, \beta_{1}=\hat{\beta}_{1}}
$$

Elements of above matrix are given by (6), (7) and (8).

\section{CONFIDENCE INTERVAL}

The most common method to set confidence bounds for the parameters is to use asymptotic normal distribution of maximum likelihood estimators, see Vander Wiel and Meeker [18]. An estimate of a population parameter may be expressed in two ways:

- Point estimate: A point estimate of a population parameter is a single value of a statistic.

- Interval estimate: An interval within which the value of a parameter of a population has a probability of occurring.

In most cases, Statisticians use confidence interval to express the precision and uncertainty as they convey additional information than point estimate. For accurate construction of confidence intervals, the variance of the MLE is needed. So in order to construct the confidence intervals for parameters, we will use the asymptotic normality of the maximum likelihood estimates.

It is known that:

$$
\left(\hat{\beta}_{0}, \hat{\beta}_{1}\right) \sim \mathrm{N}\left(\left(\beta_{0}, \beta_{1}\right), \Sigma\right.
$$

where, $\hat{\beta}_{0}$ and $\hat{\beta}_{1}$ is the MLE of $\beta_{0}$ and $\beta_{1}$ respectively and $\sum$ is the expected Fisher information matrix.

So Confidence Interval for population parameter $\beta_{0}$ is given by:

$$
\mathrm{P}\left(\mathrm{L}_{\beta_{0}} \leq \beta_{0} \leq \mathrm{U}_{\beta_{0}}\right)=\delta
$$

where $\left(\mathrm{L}_{\beta_{0}} \leq \beta_{0} \leq \mathrm{U}_{\beta_{0}}\right)$ is called two-sided $\delta 100 \%$ confidence interval for $\beta_{0} . L_{\beta_{0}}$ and $U_{\beta_{0}}$ are the lower and upper confidence limits for $\beta_{0}$. Therefore, the two sided approximate $\delta 100 \%$ confidence limits for $\beta_{0}$ and $\beta_{1}$ are given respectively as follows:

$$
\begin{aligned}
& \mathrm{L}_{\beta_{0}}=\hat{\beta}_{0}-\mathrm{z} \sigma\left(\hat{\beta}_{0}\right) \quad \mathrm{U}_{\beta_{0}}=\hat{\beta}_{0}+\mathrm{z} \sigma\left(\hat{\beta}_{0}\right) \\
& \mathrm{L}_{\beta_{1}}=\hat{\beta}_{1}-\mathrm{z} \sigma\left(\hat{\beta}_{1}\right) \quad \mathrm{U}_{\beta_{1}}=\hat{\beta}_{1}+\mathrm{z} \sigma\left(\hat{\beta}_{1}\right)
\end{aligned}
$$

\section{OPTIMIZATION CRITERIA}

An optimal test plan determines the type of stresses to be applied, level of each stress involved, methods used for stress application, minimum number of failures allocated at each stress level, optimum test duration by formulating the problem to minimize the AV of the MLE of a given $100 \mathrm{p}^{\text {th }}$ percentile at design stress.

The log of the $100 \mathrm{p}^{\text {th }}$ percentile of the lifetime $t_{p}\left(S_{0}\right)$ at the design stress $S_{0}$ is given by

$$
\hat{\psi}\left(\mathrm{S}_{0}\right)=\log \left(\mathrm{t}_{\mathrm{p}}\left(\mathrm{S}_{0}\right)\right)=\beta_{0}+\beta_{1} \mathrm{~S}_{0}+\log \left(\theta_{\mathrm{i}}(\log \mathrm{p})^{-\frac{1}{\alpha}}\right)
$$

The main purpose of this section is to explore the choice of $\tau$ in step stress accelerated life test which is obtained by minimizing AV of the MLE of a given 100 $\mathrm{p}^{\text {th }}$ percentile at design stress $\mathrm{S}_{0}$. The AV is given by:

$$
\begin{aligned}
A V\left(\hat{\psi}\left(S_{0}\right)\right) & =\log \left(t_{p}\left(S_{0}\right)\right) \\
& =A V\left(\hat{\beta}_{0}+\hat{\beta}_{1} S_{0}+\log \left(\theta_{i}(\log p)^{-\frac{1}{\alpha}}\right)\right) \\
& =K I^{-1} K^{\prime}=K \sum K^{\prime}
\end{aligned}
$$

where ,

$$
K=\left[\frac{\partial \hat{\psi}\left(\mathbf{S}_{0}\right)}{\partial \hat{\beta}_{0}} \frac{\partial \hat{\psi}\left(\mathrm{S}_{0}\right)}{\partial \hat{\beta}_{1}}\right]
$$

and $\mathrm{I}^{-1}$ is the inverse of the expected fisher information matrix given in section 2 .

So (9) becomes:

$$
\operatorname{AV}\left(\hat{\psi}\left(S_{0}\right)\right)=\frac{n\left(C-2 \mathrm{BS}_{0}+\mathrm{AS}_{0}^{2}\right)}{\mathrm{AC}-\mathrm{B}^{2}}
$$

The optimum test plan for products having inverse Weibull lifetime distribution is to find the optimal time such that the $\operatorname{AV}\left(\hat{\psi}\left(S_{0}\right)\right)$ is minimized. The minimization of asymptotic variance over $\tau$ can be achieved by solving the following equation:

$$
\frac{\partial}{\partial \tau} \operatorname{AV}\left(\hat{\psi}\left(S_{0}\right)\right)=0
$$

The optimal time $\tau^{*}$ is obtained by minimizing (13) with the help of MATLAB.

\section{SimULATION STUDY}

The main objective of this section is to illustrate how one can utilize the theoretical results discussed in the paper. In this we want to study the properties of parameter estimate and the respective confidence interval of parameters. We will also determine the optimal time which is obtained by minimizing the AV. So for the accomplishment of this task numerical example is presented. 
Example:

Existing algorithms used in $\mathrm{R}$ and MATLAB to minimize the multivariable function is unable to calculate the minimum value of the above mentioned (13). So the value of stresses $\left(S_{0}, S_{1}, S_{2}\right), \alpha, \beta_{0}, \beta_{1}$ and $\tau$ cannot be found. Hence for minimizing the above equation following program is used.

$$
\begin{gathered}
\text { For } \mathrm{n}=100, \alpha=0.9 \text { (Shape parameter) } \\
\text { for }\left(\beta_{1}=1 ; \beta_{1}<=10 ; \beta_{1}=\beta_{1}+0.05\right) \\
\text { for }\left(\beta_{0}=0.05 ; \beta_{0}<=10 ; \beta_{0}=\beta_{1}+0.04\right) \\
\text { for }\left(S_{2}=1 ; S_{2}<=10 ; S_{2}=S_{2}+0.05\right) \\
\text { for }\left(S_{1}=0.5 ; S_{1}<=10 ; S_{1}=S_{1}+0.02\right) \\
\text { for }\left(S_{0}=0.8 ; S_{0}<=10 ; S_{0}=S_{0}+0.1\right) \\
\text { for } \tau=0 ; \tau<=100 ; \tau=\tau+0.1) \\
\operatorname{Plot}\left(\operatorname{AV}\left(\hat{\psi}\left(S_{0}\right)\right)\right)
\end{gathered}
$$

By running the above pseudo code on MATLAB we find various plots between $\mathrm{AV}$ and $\tau$ for different value of parameters in given range. Among these plots, only one plot contains the minimum value of asymptotic variance for which the variables are $\tau^{*}=2.7, \mathrm{~S}_{0}=1, \mathrm{~S}_{1}=2.5, \mathrm{~S}_{2}=3.5$, $\beta_{0}=0.9$ and $\beta_{1}=1.5$. And this plot is shown as follows:

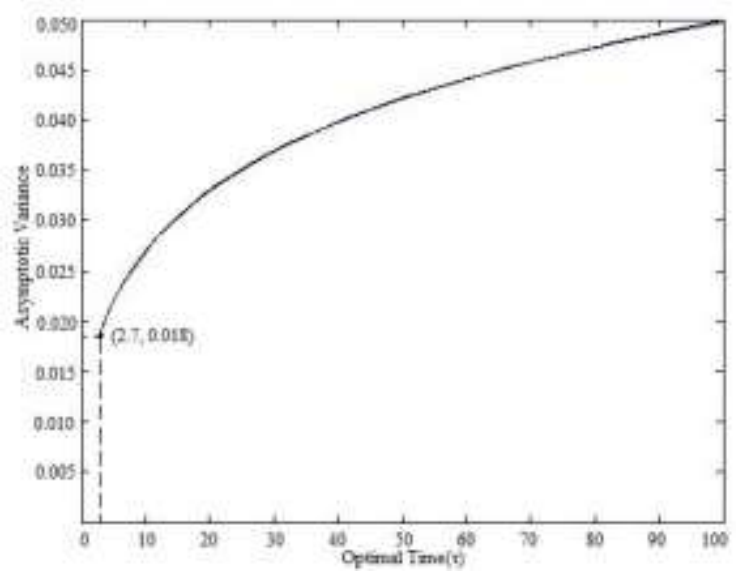

Fig. 1.

The time corresponding to minimum value of $\mathrm{AV}$ is called optimal time which is shown in the plot by $\tau^{*}$.

The steps involved in simulation procedure for example below are described as follows:

a) We simulate $n=n_{1}+n_{2}=100$ observations from K-H model (section(2)) through above mentioned values.

The following steps are followed:

- Generate a random sample of size $n$ from $\mathrm{U}(0,1)$ and arrange them in ascending order such that following conditions are fulfilled for stress $S_{1}$ and $S_{2}$ respectively:

$$
\mathrm{U}_{1 \mathrm{j}}<\exp \left[-\left(\frac{\tau}{\theta_{1}}\right)\right]^{-\alpha}
$$

and

$$
\exp \left[-\left(\frac{\tau}{\theta_{2}}\right)\right]^{-\alpha} \exp \left[-\left[\left(\frac{\tau}{\theta_{1}}\right)^{-\alpha}+1\right]\right] \leq \mathrm{U}_{2 \mathrm{j}}<\infty
$$

- Now tij are calculated as follows:

$$
\mathrm{t}_{\mathrm{ij}}= \begin{cases}\theta_{1}\left[-\log \mathrm{U}_{1 \mathrm{j}}\right]^{-\frac{1}{\alpha}} & 1 \leq \mathrm{j}<\mathrm{n}_{1} \\ \theta_{2}\left\{-\log \left[\frac{\mathrm{U}_{2 \mathrm{j}}}{-\left\{\left(\frac{\tau}{\theta_{1}}\right)^{-\alpha}-\left(\frac{\tau}{\theta_{2}}\right)^{-\alpha}\right\}}\right]\right. & 1 \leq \mathrm{j}<\mathrm{n}_{2}\end{cases}
$$

b) For the selected values of parameter of $\beta_{0} \& \beta_{1}$ of, the MLEs $\hat{\beta}_{0}$ and $\hat{\beta}_{1}$ are calculated. Now calculate estimate of $\hat{\theta}_{1}$ and $\hat{\theta}_{2}$ by

$$
\theta_{\mathrm{i}}=\exp \left(\beta_{0}+\beta_{1} \mathrm{~S}_{1}\right)
$$

c) The estimator's performance is evaluated through MSE.

$$
\text { MSE }=\frac{\sum_{\mathrm{i}=1}^{\mathrm{n}}\left(\mathrm{m}\left(\mathrm{t}_{\mathrm{i}}\right)-\mathrm{m}_{\mathrm{i}}\right)^{2}}{\mathrm{n}} ; \text { n- no. of observations. }
$$

d) Calculate the observed and expected Fisherinformation Matrix then inverted to get the asymptotic variance and Covariance matrix of the estimators for different sample sizes.

e) The two sided confidence limit with confidence level $\delta=0.95$ are constructed.

f) Finally, 95\% confidence interval coverage is also

evaluated (approx and bootstrap).

Table 1. Simple time-step stress with two stress variables simulated data

\begin{tabular}{|c|ccccc|}
\hline $\begin{array}{c}\text { Stre } \\
\text {-ss }\end{array}$ & \multicolumn{5}{|c|}{ Failure time } \\
\hline \multirow{5}{*}{} & 1.7409710 & 0.6210487 & 0.5063253 & 1.6659407 & 0.3442253 \\
& 2.1263122 & 0.5201147 & 1.0874511 & 0.7994051 & 0.5688323 \\
& 0.6176598 & 1.1802559 & 0.4691258 & 0.6387656 & 0.8261153 \\
& 2.1902748 & 2.6739849 & 0.8353804 & 1.0384966 & 0.5183677 \\
& 1.5472305 & 1.6485029 & 0.5249249 & 0.9808652 & 1.7549854 \\
& 0.6157202 & 0.5165699 & 1.2507682 & 1.6814882 & 1.6929123 \\
$\mathrm{~S}_{1}=$ & 1.1389463 & 1.6159681 & 1.6042988 & 1.3683533 & 0.7943707 \\
2.5 & 0.7561229 & 0.6310874 & 0.9460246 & 1.0763576 & 1.2558877 \\
& 1.7383601 & 1.0066371 & 1.3683906 & 1.1006016 & 0.2761212 \\
& 1.9954485 & 0.4924712 & 1.4892514 & 2.2951660 & 0.3277769 \\
& 1.6643209 & 0.8057769 & 2.0116486 & 0.2454474 & 1.1508011 \\
& 0.2118470 & 1.4312030 & 0.6142457 & 1.5209597 & 0.5894081 \\
& 0.4044710 & 2.1414378 & 2.2078172 & 0.8950349 & 2.1160841 \\
& 1.2699518 & 0.7810748 & 0.7114975 & 0.8962732 & 1.0496185 \\
& 1.4962611 & 1.1451439 & 0.8203383 & & \\
\hline \multirow{5}{*}{$\mathrm{S}_{2}=$} & 15.410737 & 4.785448 & 3.301290 & 17.781829 & 12.554463 \\
3.5 & 4.6264830 & 3.364360 & 5.656238 & 5.281917 & 33.665982 \\
& 2.7978460 & 3.096814 & 9.467507 & 4.972497 & 4.1984570 \\
& 3.1623100 & 3.971346 & 2.726722 & 4.505802 & 2.7429090 \\
& 3.5120310 & 22.67774 & 7.070494 & 4.215232 & 90.381085 \\
& 12.277686 & 3.786421 & & & \\
\hline \multirow{5}{*}{} & & & & & \\
\hline
\end{tabular}

The data in Table 1 includes 100 simulated observations from cumulative Frechet distribution (from (14)). Based on data the MLE of the model parameters $\beta_{0}$ and $\beta_{1}$ for $\tau^{*}=2.7, \alpha=3.19687 \times 10^{-7}, S_{1}=2.5, S_{2}=3.5$, $\mathrm{n}_{1}=73$ and $\mathrm{n}_{2}=27$ obtained using maxNR option of $\mathrm{R}$ software are $\hat{\beta}_{0}=11.204399$ and $\hat{\beta}_{1}=-7.455094$ and

$$
\hat{\bar{\beta}}_{0}=11.003689 \text { and } \hat{\bar{\beta}}_{1}=-7.4026122
$$


Hence,

$\hat{\theta}_{1}=0.000591219$ and $\hat{\theta}_{2}=3.420086 \times 10^{-7}$

The expected Fisher information matrix is:

$\mathrm{I}=10^{-11} \times\left[\begin{array}{ll}1.021999 & 1.803055 \\ 1.803055 & 1.875844\end{array}\right]$

The asymptotic Fisher information matrix is:

$S=\left[\begin{array}{ll}0.4547474 & 0.4547474 \\ 0.4547474 & 0.6821210\end{array}\right]$
The Variance and Covariance Matrix for MLE $\left(\hat{\beta}_{0}, \hat{\beta}_{1}\right)$ is defined as the inverse matrix of the Fisher's information matrix:

$$
\hat{S}^{-1}=\left[\begin{array}{cc}
6.597070 & -4.398047 \\
-4.398047 & 4.398047
\end{array}\right]
$$

Thus, the two-sided 95 per cent confidence intervals for $\left(\hat{\beta}_{0}\right.$ and $\left.\hat{\beta}_{1}\right)$, respectively, are

$6.979256 \leq \beta_{0} \leq 15.42954,-10.90491 \leq \beta_{1} \leq-4.005279$

Table 2. Parameter Estimation for the complete simulated sample for $\alpha=3.19687 \times 10^{-7}, S_{1}=2.5$ and $S_{2}=3.5$

\begin{tabular}{|c|c|c|c|c|c|}
\hline $\mathrm{n}$ & $\begin{array}{l}\hat{\bar{\beta}}_{0} \\
\hat{\bar{\beta}}_{1}\end{array}$ & $\begin{array}{l}\operatorname{MSE}\left(\hat{\beta}_{0}\right) \\
\operatorname{MSE}\left(\hat{\beta}_{1}\right)\end{array}$ & $\begin{array}{l}\hat{\theta}_{1} \\
\hat{\theta}_{2}\end{array}$ & \multicolumn{2}{|c|}{$\begin{array}{l}\text { 95\% CI Coverage } \\
\text { Approx } \quad \text { Bootstrap }\end{array}$} \\
\hline \multirow[t]{2}{*}{20} & 11.066834 & 0.281725 & 0.000782362 & 0.93227 & 0.94828 \\
\hline & -7.4273632 & 0.986212 & $3.27154 \mathrm{e}-07$ & 0.92871 & 0.93711 \\
\hline \multirow[t]{2}{*}{60} & 11.038761 & 0.075319 & 0.000653226 & 0.93582 & 0.93580 \\
\hline & -7.4408166 & 0.942323 & $3.077521 \mathrm{e}-07$ & 0.93625 & 0.93781 \\
\hline \multirow[t]{2}{*}{80} & 11.009762 & 0.043211 & 0.0007352203 & 0.94631 & 0.94910 \\
\hline & -7.3076521 & 0.189263 & $3.325486 \mathrm{e}-07$ & 0.94210 & 0.94730 \\
\hline \multirow[t]{2}{*}{100} & 11.003689 & 0.0043221 & 0.0005912119 & 0.95561 & 0.95291 \\
\hline & -7.4026122 & 0.182634 & $3.420086 \mathrm{e}-07^{7}$ & 0.95681 & 0.95525 \\
\hline \multirow[t]{2}{*}{120} & 11.0026481 & 0.00442831 & 0.0003827629 & 0.95262 & 0.95891 \\
\hline & -7.5815421 & 0.0513122 & $1.7736314 \mathrm{e}-07$ & 0.95431 & 0.95790 \\
\hline \multirow[t]{2}{*}{200} & 11.0026534 & 0.0021831 & 0.0003286142 & 0.95831 & 0.95913 \\
\hline & -7.599231 & 0.0321322 & $1.6786132 \mathrm{e}-07$ & 0.95672 & 0.95885 \\
\hline
\end{tabular}

Table 3. Parameter Estimation for the complete simulated sample for $\alpha=3.19687 \times 10^{-7}, \mathrm{~S}_{1}=2.9$ and $\mathrm{S}_{2}=3.6$

\begin{tabular}{|c|c|c|c|c|c|}
\hline $\mathrm{n}$ & $\begin{array}{l}\hat{\bar{\beta}}_{0} \\
\hat{\bar{\beta}}\end{array}$ & $\operatorname{MSE}\left(\hat{\beta}_{0}\right)$ & $\hat{\theta}_{1}$ & \multicolumn{2}{|c|}{$\begin{array}{l}\text { 95\% CI Coverage } \\
\text { Approx Bootstrap }\end{array}$} \\
\hline \multirow[t]{2}{*}{20} & 11.068034 & 0.078391 & 0.0002583246 & 0.95423 & 0.95487 \\
\hline & -7.4378750 & 0.086243 & $1.608645 \mathrm{e}-08$ & 0.95612 & 0.95675 \\
\hline \multirow[t]{2}{*}{60} & 11.061654 & 0.061833 & 0.000248978 & 0.96264 & 0.96968 \\
\hline & -7.4458631 & 0.083926 & $1.587544 \mathrm{e}-08$ & 0.96710 & 0.96969 \\
\hline \multirow[t]{2}{*}{80} & 11.008321 & 0.0572453 & 0.000188765 & 0.96463 & 0.96721 \\
\hline & -7.5476521 & 0.0768253 & $9.964334 \mathrm{e}-09$ & 0.96952 & 0.96967 \\
\hline \multirow[t]{2}{*}{100} & 11.003746 & 0.0527345 & 0.000178655 & 0.96742 & 0.96789 \\
\hline & -7.5626122 & 0.0582732 & $9.378544 \mathrm{e}-09$ & 0.97315 & 0.97489 \\
\hline \multirow[t]{2}{*}{120} & 11.002146 & 0.0373531 & 0.000157543 & 0.97172 & 0.97257 \\
\hline & -7.5973442 & 0.0383645 & $8.178564 \mathrm{e}-09$ & 0.97513 & 0.97845 \\
\hline \multirow[t]{2}{*}{200} & 11.0016534 & 0.019374 & 0.0001572322 & 0.97524 & 0.97598 \\
\hline & -7.5996511 & 0.001835 & $8.058956 \mathrm{e}-09$ & 0.97972 & 0.97980 \\
\hline
\end{tabular}


Table 4. Variation of optimal time $\left(\tau^{*}\right)$ for $\alpha=0.9$

\begin{tabular}{|c|c|c|c|}
\hline & $\beta_{0}=0.9, \beta_{1}=1.5$ & $\beta_{0}=1.1, \beta_{1}=1.7$ & $\beta_{0}=2, \beta_{1}=1.7$ \\
\hline $\mathrm{S}_{1}=2.5, \mathrm{~S}_{2}=3.5$ & 2.7 & 2.7 & 3.3 \\
\hline $\mathrm{S}_{1}=2.5, \mathrm{~S}_{2}=4.5$ & 2.9 & 4.2 & 4.8 \\
\hline $\mathrm{S}_{1}=4.5, \mathrm{~S}_{2}=5.5$ & 4.5 & 6.7 & 7.1 \\
\hline $\mathrm{S}_{1}=5.5, \mathrm{~S}_{2}=6.5$ & 5.8 & 9.2 & 9.8 \\
\hline $\mathrm{S}_{1}=6.5, \mathrm{~S}_{2}=7.5$ & 11.9 & 14.2 & 15.1 \\
\hline
\end{tabular}

Table 5. Variation of optimal time $\left(\tau^{*}\right)$ for different stress level

\begin{tabular}{|c|c|}
\hline & $\mathrm{n}=100, \alpha=0.9, \beta_{0}=0.5, \beta_{1}=1.5, \mathrm{~S}_{0}=1.1$ \\
\hline & $\tau^{*}$ \\
\hline $\mathrm{S}_{1}=1.65, \mathrm{~S}_{2}=5.06$ & 2.7 \\
\hline $\mathrm{S}_{1}=1.76, \mathrm{~S}_{2}=5.06$ & 2.7 \\
\hline $\mathrm{S}_{1}=1.92, \mathrm{~S}_{2}=4.18$ & 2.7 \\
\hline $\mathrm{S}_{1}=1.65, \mathrm{~S}_{2}=4.62$ & 2.8 \\
\hline $\mathrm{S}_{1}=1.87, \mathrm{~S}_{2}=4.62$ & 2.8 \\
\hline $\mathrm{S}_{1}=1.71, \mathrm{~S}_{2}=4.5$ & 2.7 \\
\hline $\mathrm{S}_{1}=2.1, \mathrm{~S}_{2}=4.48$ & 2.8 \\
\hline $\mathrm{S}_{1}=2.1, \mathrm{~S}_{2}=4.76$ & 2.7 \\
\hline
\end{tabular}

\section{CONCLUSION}

Applications of Frechet distribution is more generalized for field of reliability. It handles sensitive circuits very easily and is also used for opto-electronic device such as solar cell, photo diodes, phototransistor, light emitting devices etc. The optimum plan is subjected to total number of test unit's available, shape parameter $(\alpha), \beta_{0}$ and $\beta_{1}$. This approach of optimization is demonstrated by a numerical example, and the analysis shows that the initial value of parameters have little effect on optimal plans. Maximum likelihood estimators, Fisher information matrix (Expected and Observed) is also shown with confidence interval coverage of the estimators which is very high and stable. For some selected values of the parameters and stresses, we have shown in Fig. that as optimal time increases, the functional value (AV) also increases. Variation of optimal time for fixed shape parameter is also is also shown in table 4 . From table 5 we conclude that Optimal time is stable when parameters are fixed while stresses lies between $0.6<\mathrm{S}_{1}<2.7$ and $1.02<\mathrm{S}_{2}<3.6$. Hence stress level has less impact on optimal time which suggests that the model is appropriate in the field of high reliability components.

\section{REFERENCES}

[1] T.J. Kielpinski, and W.B. Nelson, "Optimum censored accelerated life test for normal and lognormal life distribution," IEEE Trans. Reliab., vol. R-24, pp. 310-320, 1975.

[2] W.B. Nelson, and W.Q. Meeker, "Theory for optimum censored life tests forWeibull and extreme life distribution," Technometrics, vol. 20, pp.171-177, 1978.

[3] N. Balakrishnana, and D. Han, "Optimal step-stress testing for progressively Type-I censored data from exponential distribution," Journal of Statistical Planning and Inference, vol. 139, pp. 1782-1798, 2009.
[4] W.B. Nelson, "Accelerated Testing, Statistical Models," Test Plans and Data Analysis, Wiley, New York, NY, 1990.

[5] C. Xiong, "Step stress model with threshold Parameter," Journal of Statistical Computation and Simulation, vol. 63, pp. 349-360, 1998.

[6] A.J. Watkins, "Commentary: inference in simple stepstress models," IEEE Transactions on Reliability, vol. 50, pp. 36-37, 2001.

[7] W. Zhao, and E. A. Elsayed, "A General accelerated life model for step-stress testing." IIE Transactions, vol. 37, pp. 1059-1069, 2005.

[8] N. Balakrishnan, E. Beutner, and M. Kateri, "Order Restricted Inference for Exponential Step-Stress Models," IEEE Transactions on Reliability, vol. 58, pp. 132-142, 2009.

[9] K.P. Yeo, and L.C. Tang, "Planning step-stress life-test with a target accelerated factor," IEEE Transactions on Reliability, vol. 48, pp. 61-67, 1999.

[10] R. Miller, and B. Nelson, "Optimum simple step-stress plans for accelerated life testing," IEEE Transactions on Reliability, vol. 32, pp. 59-65, 1983.

[11] D.S. Bai, M.S. Kim, and S.L. Lee, "Optimum simple stepstress accelerated life tests with censoring," IEEE Trans. I Reliab., vol. 38, pp. 528-532, 1989.

[12] H. Khamis, and J. Higgins, "A New Model for Step-Stress Testing," $2^{\text {nd }}$ ed., vol. 47, pp. 131-134, June 1998.

[13] A. Ali Ismail, and M. Ammar, "Optimal Design of StepStress Life Test with Progressively type-II Censored Exponential Data," International Mathematical Forum, 4, vol. 40, pp. 1963 - 1976, 2009.

[14] L.C. Tang, L.C. Sun., T.N. Goh, and H.L. Ong., "Analysis of step-stress accelerated-life-test data:new approach," IEEE Trans Reliab., 1 ${ }^{\text {st }}$ ed., vol. 45, pp. 69-74, 1996.

[15] G.K. Bhattacharyya, and Z. Soejoeti, "A tampered failure rate model for step-stress accelerated life test," Communications in Statistics: Theory and Methods, vol. 18, pp. 1627-1643, 1989.

[16] G.K. Bhattacharyya, "Parametric models and inference procedures for accelerated life tests. Presented as an invited paper for 46th session of the International Statistical Institute Meeting," Tokyo, Japan, 8-16 September 1986.

[17] K.A. Doksum, and A. Hoyland, "Models for variablestress accelerated life testing experiments based on Wiener process and inverse Gaussian distribution," Technometrics, vol. 34, pp. 74-82, 1991.

[18] S.A Vander Wiel, and W.Q. Meeker, "Accuracy of Approximate Confidence Bounds using Censored Weibull Regression Data from Accelerated Life Tests," IEEE Tran.On Reliability, $3^{\text {rd }}$ ed., vol. 39, pp. 346-351, August 1990.

\section{Authors' Profiles}

Sana Shahab is a Ph.D. candidate in department of Statistics \& Operations Research at Aligarh Muslim University, Aligarh (U.P.), India . She has received her M.Sc. degree in statistics from A.M.U. in 2010 and B.Sc. degree from the same in 2008. Her area of research is Accelerated Life Test Design. She has published 3 research papers in journals of statistics and has attended many international conferences and workshop related to her research area.

Arif-Ul-Islam is working as professor in department of Statistics \& Operations Research in Women's College at Aligarh Muslim University, Aligarh (U.P.), and India. He has 
more than thirty years of teaching experience. He received his doctorate degree from A.M.U. in 1978. His area of research is Stochastic Process and Reliability Theory. He received his M.Sc. \& B.Sc. degree in 1974 and 1972 respectively from same university. He is Gold Medalist in M.Sc.

$\mathrm{He}$ has taught at five different Universities in India and abroad. He initiated his career at AMU Aligarh, as Lecturer in 1978. He has taught at University of Kashmir-India, Basrah University-Iraq, Gharyonus University Banghazi-Libya and Gonder University-Ethopia. He has worked as University Grant Commission research associate. $\mathrm{He}$ is member of Indian Science Congress and Indian Statistical Association. He has published more than twenty papers in national and international journals of statistics in the field of reliability and life testing. Along with this he has also developed a reliability model for life testing, widely accepted and cited by many researchers in the field of reliability theory. His reliability model is known as Mukherji-Islam failure model. He has guided many Ph.D. students and M.Phil. students, in upcoming area of Accelerated life testing \& Software Reliability. Currently he is supervising five scholars in his department. Besides above, he is a great philosopher and debater.

How to cite this paper: Sana Shahab, Arif-Ul-Islam,"Graphical Representation of Optimal Time for a Step-Stress Accelerated Life Test Design Using Frechet Distribution", International Journal of Information Technology and Computer Science(IJITCS), vol.6, no.12, pp.74-81, 2014. DOI: 10.5815/ijitcs.2014.12.10 